\title{
Have Sentiments Influenced Malaysia's Stock Market Volatility During the 2008 Crisis?
}

\author{
Nathrah Yacob*
}

\author{
Taylor's Business School, Taylor's University Lakeside Campus, Malaysia
}

\begin{abstract}
This paper examined the effects of both macro-economic and investor sentiment on the volatility of the Malaysian stock market, during the 2008 global financial crisis. However, as the measurement for investor sentiment is unavailable, we constructed an investor sentiment composite index from a number of proxies, namely; the stock market turnover, number of Initial public offerings (IPO) and its initial returns, advance decline ratio, and consumer sentiment index by employing a strict process of Factor analysis with Principal component analysis' extraction. By employing Autoregressive Distributive Lags (ARDL) model, we observed the failure of macroeconomic fundamentals to significantly predict the Malaysian stock market's volatility during the crisis period while investor sentiment was a significant factor that influenced the market. These findings support the notion that investors tend to behave irrationally during crisis periods and these may assist practitioners in formulating specific investment strategies during crucial periods in order to gain abnormal returns.
\end{abstract}

Keywords: Macroeconomic fundamentals, investor sentiment, global financial crisis, volatility, Malaysia stock market.

\section{INTRODUCTION}

Knowledge on stock market's volatility is crucial as it may affect investors' decisions on investment, which ultimately may affect the growth prospect of an economy. Lack of information about the causes of volatility may result in employing inaccurate investment strategies by investors. It may also conceal the appropriate measures that should be taken by regulators and policymakers to eradicate potential bubbles caused by irrational exuberance. Researchers have pondered over the cause of excess volatility in stock markets (Shiller, 1981, 1987). Theoretically, excess volatility proposes that people act irrationally on the information they receive, thus creating unexplained volatility in the stock market. Since then, numerous attempts have been made to identify the roots of this anomaly.

Therefore, in searching for confirmation on the possible factors that may have predicted the volatility of Malaysian stock market, this study examines the data of 13 years from Bursa Malaysia's stock exchange and Department of statistics, Malaysia to provide evidence to support or contradict the suggestions made by Angabini and Wasiuzzaman (2011); Kim and Nofsinger (2008); Zakaria and Shamsuddin, (2012). The researchers suggested that Malaysian investors may be irrational as their findings have evident little value of

*Address correspondence to this author at the Taylor's Business School, Taylor's University Lakeside Campus, Malaysia; Tel: +60356295676/+60123064798; Fax: +603-78451975;

E-mail: Nathrah.YacobMohdYacob@taylors.edu.my

JEL classification: G12 Asset pricing macroeconomic fundamentals in predicting stock returns. However, none of the researchers have specifically identified and measured the variable that may represent irrational investor sentiment in their studies. In that respect, this paper intended to(i) construct the composite index of investor sentiment, (i) examine whether there are effects of macroeconomic variables (inflation, money supply, interest rate, and exchange rate) on the volatility of the stock market, and (ii) examine whether there was any effect of nonmacroeconomic fundamental variable (investor sentiment), on the volatility of the Malaysian stock market. This study focused on the 2008 global financial crisis that persisted for 38 months as identified by Bai Perron's multiple break test. The study on the period of global crisis is crucial as uncontrolled extreme volatility during volatile stock market may eventually lead to further financial crisis, which is likely to affect the economy on a larger scale. The evidence of macroeconomic fundamentals as drivers of the volatile market has been inconclusive as different researchers reported different findings and impacts of economic variables in different countries ${ }^{1}$. This suggests that there are factors other than macro-economic fundamentals that may explain the movement of stock prices. Stemmed from both perspectives, this paper assesses the effects of possible influencing factors, both fundamental and non-fundamental on stock market volatility to observe whether the status quo in developed countries holds true in a different environment, i.e. emerging markets.

${ }^{1}$ Beltratti and Morana, 2002; Diebold and Yilmaz, 2008; Engle, Ghysels and Sohn, 2013; Rahman, Sidek and Tafri, 2009. 
The evidence of psychological biases, whether theoretical, or empirical, has emerged as an important factor influencing investment decisions in Asia. It has long been argued that a collective-oriented society is among the factors leading to behavioural bias. This notion is supported by Kim and Nofsinger (2008) which examined the socially collective behaviours observed in Asian communities and cultures including Malaysia. In addition to culture, the absence of market makers proves another significant reason in warranting the research on the Malaysia's stock market. Technically, the Malaysian stock market is an order-driven market otherwise known as an auction market in which prices are determined by the publication of investors' orders buying or selling shares without the intervention of market makers. Hence, the movement of stock prices is transparent to the sentiment of stock market participants, observing by their behaviours in stocks trading.

Therefore, the main contribution of this paper is the construction of the investor sentiment index which is currently not available in the emerging stock market, specifically in the Malaysia's stock market. Although similar index may have been constructed in the developed market, no studies have included the same proxies as highlighted in this paper. Moreover, no other studies have examined macroeconomic and nonmacroeconomic fundamentals which are from two different paradigms in asset pricing and simultaneously tested the variables in one econometric model. The robustness of the index was then tested whether it may be used in detecting the influences of nonmacroeconomic fundamental on the stock market volatility. In doing so, the next section begins with description of the proxies and measurement included in constructing the investor sentiment composite index and the methodology applied to test the robustness of the index.

\section{LITERATURE REVIEW}

Some researchers attempted to establish a link between the anomalous performances with macroeconomic fundamentals (Davis \& Kutan, 2003; Officer, 1973; Schwert, 1989) whilst others associated stock market volatility with human emotion. It is worth noting that the most popular explanatory factor of stock market volatility is the volatility of macroeconomic variables. For instance, Schwert (1989) analysed stock market volatility and macroeconomic volatility and found that although the stock market volatility was correlated with aggregate leverage, it only marginally have predicted the volatility of the stock movement. As an influential study on stock market volatility, the work of Schwert (1989) was extended by Davis and Kutan (2003) who studied inflation and real output to the stocks' volatility for 13 developed and industrialised countries. Their results were consistent with those of Schwert (1989) with weak evidence of the predictive power of macroeconomic volatilities on the stock market volatilities in data for the United States as well as in other countries in their sample. The inconclusive findings in associating macroeconomic fundamentals with the stock return volatility in the Malaysian stock market returns during the global crisis began when Law (2006) and Angabini and Wasiuzzaman (2010) found higher volatility in the Kuala Lumpur Composite Index during the 1998 Asian financial crisis and 2008 global financial crisis. They indicated that these scenarios were attributed to the overreaction behaviour by investor sentiment during high risk or crisis points. This is further supported by the findings of Zakaria and Shamsuddin (2012) which found little evidence on the effect of macroeconomic variables on Malaysian stock market volatility. Hence, it is apparent that regardless of the environment of studies, both developed and developing stock markets posed similar reactions of excess volatility during crises or non-crises.

\section{METHODOLOGY}

\section{Modelling the Volatility of Kuala Lumpur Composite Index}

This study adopts the measurement of stock market volatility introduced by French, Schwert, and Stambaugh (1987), where standard deviation and variance are calculated from monthly Kuala Lumpur Composite Index returns from the sample data. The data are in monthly frequency from the year 2000 to 2012. Following French et al. (1987), the volatility is estimated as the square root of sum of squared daily return plus twice the sum of adjacent returns. The formula is as follows:

$$
O_{m, t 2}=\sqrt{\sum_{i=1}^{N t} r_{i, t 2}^{2}+2 \sum_{i=1} r_{i, t} r_{i, t+1}}
$$

Where $N_{t}$ is the daily returns of $r_{i, t}$ in month $\mathrm{t}$ and $r_{i, t+1}$ is the returns of month $t+1$. The computed standard deviations are then converted into percentages to simplify the interpretation of results. This measurement highlights the fluctuations of Kuala Lumpur Composite Index from 2007 to 2010 shown by Figure 1 whereby periods of high volatility from 2007 to early 2010 are 


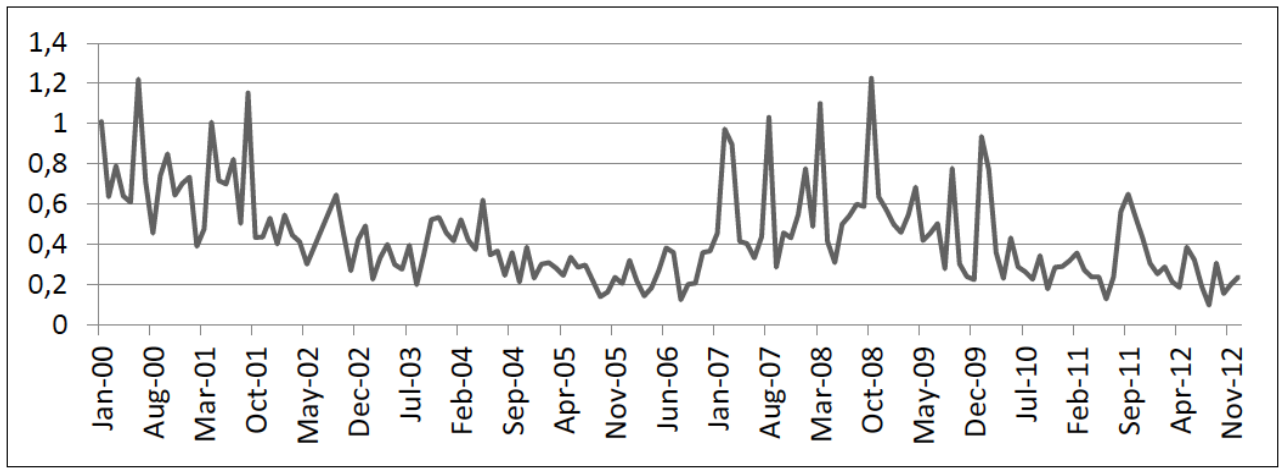

Figure 1: The volatility of KUALA LUMPUR COMPOSITE INDEX from 2000 to 2012.

observed which is consistent with the global financial crisis that began in late 2007 .

Figure 1 illustrates the volatility of the Kuala Lumpur Composite Index which is measured by standard deviations has reached its highest point in October $2008(1.225 \%)$ and slightly exceeded the extreme volatility periods in June $2000(1.219 \%)$. The two periods are mainly related to the phenomenal crises which affected many countries including Malaysia. Nevertheless, there are also periods of tranquillity wherein minor fluctuations of Kuala Lumpur Composite Index were observed from October 2001 to August 2006 , with the highest standard deviation at $0.65 \%$. Prior to modelling the causal or predictive relationship between macroeconomic fundamentals, investor sentiment and the volatility of the Kuala Lumpur Composite Index, the volatility of Kuala Lumpur Composite Index is tested for structural breaks to identify the episodes of unusual volatility that coincide with the 2008 global crisis.

Since this study focuses on the 2008 global financial crisis period where indicators of the beginning and ending of the crisis are unclear, we identify these periods by capturing the structural breaks during the sample period. For this step, we consider an effective methodology where multiple structural breaks can be detected without prior knowledge of the dates. The methodology is known as the Bai-Perron's (Bai \& Perron, 1998, 2003a, 2003b) structural test which accommodates multiple unknown breakpoints. In this analysis, the double maximum test is selected where the null hypothesis without structural breaks is tested against an unknown number of breaks. This test uses an equal weight version where estimates of the break points are obtained using the global maximisation of the sum squared residuals. In order to construct the optimal bandwidth or the HAC estimator, each element of the vector is estimated with quadratic spectral kernel with Autoregressive (1). Since the residuals are serially uncorrelated, the optimal trimming is selected at $\epsilon=0.15$ where the maximum break is set at 5 . The result is exhibited in Table 1.

Table 1: Structural Breaks Determined by Bai-Perron's Multiples Break Test

\begin{tabular}{|c|c|c|}
\hline Breaks & Coefficient & t-statistics \\
\hline \hline 2000M4-2001M2 & $0.007^{\star * *}$ & 32.925 \\
\hline 2001M3-2004M7 & $0.004^{\star * *}$ & 17.695 \\
\hline 2004M8-2006M12 & $0.003^{\star * *}$ & 15.819 \\
\hline 2007M1-2010M2 & $0.006^{\star * *}$ & 18.422 \\
\hline 2010M3-2012M12 & $0.0029^{\star * *}$ & 8.077 \\
\hline Adj. R squared & 0.4716 & D.W 1.994 \\
\hline
\end{tabular}

Note: ${ }^{* \star *}$ denotes the $1 \%$ significance level.

Table 1 indicates that there are five significant structural breaks from 2000 to 2012. The breaks are consistent with the number of stock market crashes and financial crises that took place during those periods. The crises include the Dot.com bubble and burst during 2001 that saw the collapse of many internet based companies in the United States (US) as well as Malaysia. The September 11 attacks in the US worsened the situation. Another structural break where higher volatilities were found was during the 2008 global financial crisis. In accordance to Bai-Perron's structural test, the significance period was identified to fall between January 2007 and February 2010, which persisted for 38 months.

\section{Proxies of Macroeconomic Variables}

This study begins by acquiring information on Malaysian macroeconomic variables consisting of the base lending rate to represent interest rate, consumer price index to measure inflation rate, and the effective exchange rate provided by Bank of International 
Settlement (BIS) to reflect the exchange rate. The industrial production index and the broad money supply are then used to represent real output and money in circulation. The dependent variable is the volatility of the well-known Kuala Lumpur Composite Index. All series are logged transformed in an attempt to linearise the data as well as to simplify the interpretation of the results. The predictive value of each of the macroeconomic variables on the volatility of the Kuala Lumpur Composite Index is examined. Hence, the first hypothesis tested is:

H1: Macroeconomic variables (BLR, CPI, EER, IPI, and $M 3$ ) have no significant causal relationship with the volatility of Kuala Lumpur Composite Index during the Global Financial Crisis.

As suggested by Bai-Perron's multiple breaks test in Table 1, the phase that coincides with the global crisis is identified as the period from January 2007 to February 2010. The number of observations is limited to 38 months, which suffices for the next stage of analysis. This is because as a common rule of thumb in statistics, a minimum of 30 observations is sufficient for analyses (Hog \& Tanis, 2005). Since the variables hold different order integration, the appropriate model to examine the relationship between macroeconomic and the volatility of the stock market is the $\operatorname{ARDL}(p, q)$ model. Table 2 exhibits the relationship between the variables modelled by ARDL $(1,1,1,1,1,1)$ that indicates none of the independent variables possess significant relationships with the volatility of the Kuala Lumpur Composite Index; neither the long term relationship nor short term dynamics between the variables. Nevertheless, for confirmation, the ARDL bound test is applied to check if the coefficients of $\mathrm{BLR}_{\mathrm{t}-1}, \mathrm{CPI}_{\mathrm{t}-1}$, $E E R_{t-1}, I P I_{t-1}$, and $M 3_{t-1}$ are zero in the estimated model. The coefficient bound test is conventional cointegration testing which examines the absence of a long-run equilibrium relationship between the variables.

The results conclude that macroeconomic fundamentals fail to prove neither their long term nor short term relationships with the movement of stock market volatility during the 2008 global financial crisis. The model is tested for autocorrelation and heteroscedasticity and is free from the influence of both. In extension to the ARDL $(1,1,1,1,1,1)$ model which generates inconclusive evidence of a long term equilibrium between the variables, the model is reestimated to fit a restricted ECM. The results are displayed in Table 3.
Table 2: ARDL $(1,1,1,1,1,1)$ between BLR, CPI, EER, IPI, M3 and Volatility of Kuala Lumpur Composite Index during 2008 Global Financial Crisis

\begin{tabular}{|c|c|c|c|}
\hline Variable & Coefficient & & t-Statistic \\
\hline C & -0.274 & & -0.6660 \\
\hline $\mathrm{VKLCl}_{-1}$ & $-3.838^{\star *}$ & & -2.9586 \\
\hline$B L R_{t-1}$ & 0.018 & & 0.4311 \\
\hline $\mathrm{CPI}_{\mathrm{t}-1}$ & 0.006 & & 1.7004 \\
\hline $\mathrm{EER}_{\mathrm{t}-1}$ & 0.002 & & 0.0197 \\
\hline$|P|_{t-1}$ & 0.037 & & 0.6760 \\
\hline$M 3_{t-1}$ & 0.033 & & 0.8606 \\
\hline$\Delta \mathrm{VKLCl}_{-1}$ & $2.297^{*}$ & & 2.1374 \\
\hline$\Delta \mathrm{VKLCl}_{-2}$ & $1.709^{*}$ & & 2.0316 \\
\hline$\Delta \mathrm{VKLCl}_{-3}$ & 1.0736 & & 1.6742 \\
\hline$\Delta \mathrm{VKLCl}_{-4}$ & 0.5361 & & 1.1443 \\
\hline$\Delta \mathrm{VKLCl}_{\mathrm{t}-5}$ & 0.2421 & & 0.8699 \\
\hline$\Delta \mathrm{BLR}_{\mathrm{t}-1}$ & 0.0070 & & 0.0723 \\
\hline$\Delta \mathrm{CPI}_{\mathrm{t}-1}$ & -0.0009 & & -0.2004 \\
\hline$\Delta \mathrm{EER}_{\mathrm{t}-1}$ & 0.0600 & & 0.3617 \\
\hline$\Delta \mathrm{LIPI}_{\mathrm{t}-1}$ & -0.0263 & & -0.6393 \\
\hline$\Delta \mathrm{M}_{\mathrm{t}-1}$ & -0.0273 & & -0.2108 \\
\hline $\mathrm{R}^{2}$ & 0.757605 & D.W & 2.06 \\
\hline AIC & -8.771557 & LM Test & 3.043 \\
\hline SC & -7.985177 & ARCH Test & 0.467 \\
\hline
\end{tabular}

Note: ${ }^{* *}$ and ${ }^{*}$ denote $5 \%$ and $10 \%$ significant levels, respectively.

Table 3: Multiple Regression Model between BLR, CPI, EER, IPI, M3 and Volatility of Kuala Lumpur Composite Index

\begin{tabular}{|c|c|c|c|}
\hline Variable & Coefficient & & t-Statistic \\
\hline \hline $\mathrm{C}$ & 0.0003 & & 0.6695 \\
\hline $\mathrm{Z}_{\mathrm{t}-1}$ & $-1.333^{* * *}$ & & -4.0784 \\
\hline$\Delta \mathrm{VKLCI}_{\mathrm{t}-1}$ & 0.2372 & & 1.1936 \\
\hline$\Delta \mathrm{BLR}_{\mathrm{t}-1}$ & 0.0017 & & 0.18126 \\
\hline$\Delta \mathrm{CPI}_{\mathrm{t}-1}$ & 0.0021 & & 0.71366 \\
\hline$\Delta \mathrm{EER}_{\mathrm{t}-1}$ & -0.0052 & & -0.0485 \\
\hline$\Delta \mathrm{LIPI}_{\mathrm{t}-1}$ & -0.0298 & & -1.3287 \\
\hline$\Delta \mathrm{M}_{\mathrm{t}-1}$ & -0.1118 & & -1.2965 \\
\hline $\mathrm{R}^{2}$ & 0.641 & D.W & 2.09 \\
\hline $\mathrm{AIC}$ & -9.077 & LM Test & 1.692 \\
\hline $\mathrm{SC}$ & -8.722 & ARCH Test & 0.826 \\
\hline
\end{tabular}

Note: ${ }^{* *}$ denotes the $1 \%$ significance level.

It is evident that the coefficient of the errorcorrection term, $\mathrm{Z}_{\mathrm{t}-1}$, is negative and significant at one 
percent level. The magnitude of this coefficient implies that $1.33 \%$ of any disequilibrium between all macroeconomic variables and Kuala Lumpur Composite Index is corrected within period of one month. The final model is free from auto correlation and $\mathrm{ARCH}$ effect as shown by the $\mathrm{LM}$ and $\mathrm{ARCH}$ tests whereby the hypotheses of no serial correlation and heteroscedasticity are not rejected respectively. The next section attempts to search for the determinant of volatility with regard to the involvement of nonfundamental factor, which in this case, is investor sentiment.

\section{Proxies of Investor Sentiment}

Despite the lack of a unanimously accepted definition of investor sentiment, new models have been progressively developed to measure the concept and have applied it to test the predictability in future returns of stocks held by investors. For instance, Neal and Wheatley (1998) documented the forecasting power of three popular investor sentiment measures: the level of discounts on closed-end funds, the ratio of odd lot sales to purchases, and net mutual fund redemptions on the size premium predictions ${ }^{2}$. To a large extent, the measure by Baker, Wurgler and Yuan, (2012) is by far the most relevant and practical as it includes all other proxies that have previously been used in other studies (Baker \& Stein, 2004; Baker \& Wurgler, 2006; Baker \& Wurgler, 2007). Hence, following Baker et al. (2012), we include as many available proxies in the Malaysian stock market as possible to form a composite index based on a common component of the underlying factors. The most appropriate proxies that measure investor sentiment will be determined by Factor Analysis with the extraction of Principal Component Analysis. Discussion on each of the proxies will follow in the next section.

The first proxy is the oft-quoted stock market turnover (TURN) which was adopted as the first proxy to the investor sentiment as was tested in Baker and Stein (2004) and Baker and Wurgler (2007). This is shown in equation (2):

$$
T U R N=\frac{\text { Monthly trading volume }}{\text { Average shares listed }}
$$

\footnotetext{
${ }^{2}$ Other researchers (e.g. Brown, 1999; Lee, Shleifer, \& Thaler, 1991) further extend that the investor sentiment is associated with greater volatility of closedend investment funds. Baker, Wurgler, Yuan (2012) support the application of indirect proxies to represent sentiment such as closed end fund discount, market turnovers and initial public offers' data.
}

The second proxy is the number of monthly initial public offerings (NIPO). Past studies have found that fluctuations of NIPO are caused by the euphoria of investor sentiment or behaviour towards the stock market or current economy (Derrien, 2005; Dorn, 2009; Lowry, 2003; Ritter \& Welch, 2002; Yung, Colak, \& Wang, 2008). NIPO is computed as the number of IPOs that goes public during the month of study. The third proxy is the initial returns of Initial Public Offerings (RIPO) which represents the average initial first day return on a particular month's offerings. RIPO is computed as the closing price of the first day less the offer price (Aggarwal, Leal, \& Hernandez, 1993; Chan, Frankel, \& Kothari, 2004) and are equally weighted across the board, as given in equation (3):

$$
R I P O=\left(\frac{P_{i 1}-P_{i 0}}{P_{i 0}}\right)
$$

Where, $P_{i 0}$ is the first day closing price, and $P_{i 0}$ is the offer price.

The fourth proxy of investor sentiment is the monthly frequency of the advancers and decliners stocks (ADV) (Brown \& Cliff, 2005). The data are truncated at zero as the numerator and denominator of these variables have the tendency to move in the opposite direction. This is shown in equation (4).

$A D V=\frac{\text { Number of Advancers }_{t}}{\text { Number of Decliners }}$

Finally, the fifth proxy used is the consumer sentiment index (CSI) or sometimes known as consumer confidence $(\mathrm{CCl})$ index (Bandopadhyaya \& Jones, 2006; Fisher \& Statman, 2003; Lemmon \& Portniaguina, 2006; Schmeling, 2009). In Malaysia, the index is published by the Malaysian Institute of Economic Research (MIER) and is available only on a quarterly basis. To promote consistency with other proxies, the CSI is interpolated to monthly frequency using a simple linear method. Each series is standardised by subtracting the mean and divided by the standard deviation in each data prior to application of Factor Analysis.

\section{RESULTS AND FINDINGS}

\section{Construction of the Raw Investor Sentiment Composite Index (ISCI)}

As discussed in the previous sub-section, the proxies include the stock market turnover (TURN), 
Table 4: Total Variance Explained by each Component

\begin{tabular}{|c|c|c|c|}
\hline \multirow{2}{*}{ Principal Components } & \multicolumn{2}{|c|}{ Initial Eigenvalues } \\
\cline { 2 - 4 } & Total & \% of variance & Cumulative \% of variance \\
\hline \hline 1 & 2.529 & 25.286 & 25.286 \\
\hline 2 & 2.230 & 22.297 & 47.583 \\
\hline 3 & 1.634 & 16.336 & 63.920 \\
\hline
\end{tabular}

number of IPOs (NIPO), initial returns of IPOs (RIPO), advance and decline ratios (ADV), as well as the consumer sentiment index (CSI) which data are transformed into log variables prior to employing Factor Analysis.

Initial factors are usually determined by Factor Analysis with PCA extraction based on the total variation in the data. Consistent with Baker and Wurgler (2006), the first stage index (FSI) is formed from all the five variables and their designated lags. The FSI is the first principal component (PC1) which is calculated from the weighted linear combination of the variables that accounts for the largest amount of the total variation in the data. Meaning, FSI is the linear combination of the proxies as shown from the equation (5) below:

$$
\begin{aligned}
& F S I=W_{1} T U R N_{t}+W_{2} T_{U R N_{t-1}}+W_{3} N_{I P O_{t}}+W_{4} N I P O_{t-1} \\
& +W_{5} R I P O_{t}+W_{6} R I P O_{t-1}+W_{7} A D V_{t}+W_{8} A D V_{t-1} \\
& +W_{9} C S S I_{t}+W_{10} C S I_{t-1}
\end{aligned}
$$

The weights (W) as shown in equation (5) have been chosen to maximise the quantity of variance. The variance obtained by each principal component is shown in Table 4 where Principal Component 1 has the highest percentage of variance $\left(\sigma^{2}=25.29 \%\right)$ followed by Principal Component 2 and Principal Component 3.

The first principal component was adopted by Baker and Wurgler (2006) as the first stage factor which comprises all variables including their respective lags. With reference to Baker and Wurgler (2006), Table 5 exhibits the non-parametric Pearson's correlation between the proxies and the first stage index. This step is taken to determine the appropriate timing that the proxies represent in constructing the composite index. The proxies with significant $\mathrm{FSI}$ correlations are selected as the timing effects. The correlation with FSI is shown on Column 12 (Table 5) where according to each of the variables' significant value, TURN, RIPO, $A D V$ and $C S I$ have lagging effect on the first stage index whilst NIPO has a current effect on the first stage index. The timings of TURN, NIPO, and RIPO are therefore consistent with the findings in Baker and Wurgler $(2006,2007,2012)$. However, the effects of $A D V$ and $C S I$ to the sentiment are yet to be tested in previous studies hence a comparison could not be made with the findings of this study.

Table 5: The Correlation between Proxies with Lags and First Stage Index

\begin{tabular}{|c|c|}
\hline & First Stage Index $_{\mathbf{t}}$ \\
\hline \hline TURN $_{\mathbf{t}}$ & 0.106 \\
\hline TURN $_{\mathrm{t}-1}$ & $0.125^{*}$ \\
\hline NIPO $_{\mathbf{t}}$ & $0.445^{* * *}$ \\
\hline NIPO $_{\mathrm{t}-1}$ & $0.437^{* * *}$ \\
\hline RIPO $_{\mathbf{t}}$ & $0.432^{* * *}$ \\
\hline RIPO $_{\mathrm{t}-1}$ & $0.462^{* * *}$ \\
\hline ADV $_{\mathbf{t}}$ & -0.005 \\
\hline ADV $_{\mathrm{t}-1}$ & $0.145^{*}$ \\
\hline $\mathbf{C S I}_{\mathbf{t}}$ & $0.903^{* *}$ \\
\hline $\mathbf{C S I}_{\mathrm{t}-1}$ & $0.909^{* * *}$ \\
\hline
\end{tabular}

Note:

i. ${ }^{* * *},{ }^{* *},{ }^{*}$ denote the $1 \%, 5 \%$ and $10 \%$ significance level, respectively.

ii. TURN $N_{t}$ and TURN $_{\mathrm{t}-1}$ represent stock market turnover in current and onemonth lag. NIPO ${ }_{t}$ and $\mathrm{NIPO}_{\mathrm{t}-1}$ represent the number of IPOs in current and its one-month lag. $\mathrm{RIPO}_{\mathrm{t}}$ and $\mathrm{RIPO}_{\mathrm{t}-1}$ represent initial return of IPOs in current and its one-month lag. $A D V_{t}$ and $A D V_{t-1}$ represent advance versus decline stocks in current and its one-month lag. $\mathrm{CSI}_{\mathrm{t}}$ and $\mathrm{CSI}_{\mathrm{t}-1}$ represent the consumer sentiment index published by MIER in current and its one-month lag.

The next step is to run the Factor Analysis with PCA extraction for five proxies with their respective lags in order to finalise the construction of the investor sentiment composite index. Table 6 exhibits the factor loadings which comprise correlations for each proxy according to their respective factors. Principal component 1 with the largest variance of the data is defined as the investor sentiment composite index.

The results in Table 6 show that $\mathrm{CSI}_{\mathrm{t}-1}$ has the strongest correlation $(\rho=0.842)$ with investor sentiment composite index. The second highest correlation with the composite index is the RIPO ${ }_{t-1}$ followed by $\mathrm{NIPO}_{t}$ with rho $(\rho)$ of $0.427, \operatorname{TURN}_{\mathrm{t}-1}(\rho=0.27)$, and finally $A D V_{t-1}$ which has weak correlation at 0.01 . With regard to the signs of each proxy to investor sentiment 
composite index, all proxies enter the index with positive relationships. This shows that an increase in TURN $_{t-1}$, NIPO $_{t}$, RIPO $_{t-1}, A D V_{t-1}$, and CSI $_{t-1}$ increases the value in the composite index. These observations are consistent with Baker and Wurgler's (2006) findings, however, the strength of proxies contributed to the Baker and Wurgler's investor sentiment composite index is different than the proxies from this study, where, all proxies influence the index at similar level of strengths.

Table 6: Factor Loadings for PC1, PC2 and PC3

\begin{tabular}{|c|c|c|c|}
\hline & \multicolumn{3}{|c|}{ Principal Component } \\
\cline { 2 - 4 } & $\mathbf{1}$ & $\mathbf{2}$ & $\mathbf{3}$ \\
\hline \hline TURN $_{\mathrm{t}-1}$ & 0.27 & -0.821 & -0.228 \\
\hline NIPO $_{\mathbf{t}}$ & 0.427 & 0.756 & -0.154 \\
\hline RIPO $_{\mathrm{t}-1}$ & 0.571 & 0.138 & 0.449 \\
\hline ADV $_{\mathbf{t}-1}$ & 0.01 & 0.029 & 0.911 \\
\hline $\mathbf{C S I}_{\mathrm{t}-1}$ & 0.842 & -0.06 & -0.046 \\
\hline
\end{tabular}

Next stage in constructing the composite index is the computation of the factor score, which is a weighted linear combination of the original series similar as equation (6). The procedure leads to a parsimonious composite index:

$$
\begin{aligned}
& I S C I=0.28 T U R N_{t-1}+0.29 N I P O_{t}+0.412 R I P O_{t-1} \\
& +0.049 A D V_{t-1}+0.669 C_{S I-1}
\end{aligned}
$$

The factor score is the weighted sums of the original standardised series thereby making up for the composite index illustrated in Figure 2.

As shown in Figure 2, the investor sentiment composite index (ISCI) is constructed from raw data of five proxies made of negative and positive sentiments. Sentiment was at its highest in August 2005 (ISCl=
2.67) and in March 2011 (ISCI= 2.54). The apparent episode was during the global financial crisis in 2007 to 2008, where the $I S C I$ was at its lowest point $(I S C I=-$ 3.28) which affected the Malaysian economy and other countries. However, beginning in mid-2010, the pattern seems to have reversed to positive territory until the end of 2012.

As discussed in the methodology section, the raw proxies may include some influences of macroeconomic fundamental therefore, may be biased and inaccurate to represent irrational behaviour investor sentiment. Therefore, we constructed a critical measure to obtain the true investor sentiment representative that is consistent with its definition. Each proxy is regressed with macroeconomic variables in order to obtain a cleaner measure of investor sentiment as demonstrated by Baker and Wurgler (2006). Since the objective of this method is to obtain a cleaner measure of net macroeconomic fundamentals in the investor sentiment composite index, the variables are regressed into a parsimonious model. The residuals, also known as noise factor, from the model are identified as the cleaner index.

\section{Construction of a Cleaner Index for Investor Sentiment}

The ARDL $(p, q)$ model has a number of advantages over VAR or ECM. Firstly, it estimates the relationships in each level. This is because the model suggests that once the order of cointegration is recognised, the relationship can be estimated with the OLS standard. Secondly, it introduces the bound test that allows the mixture of $\mathrm{I}(0)$ and $\mathrm{I}(1)$ variables as regression. Thirdly, the approach only involves a single equation set up, which makes it easier to implement and interpret. Last but not least, different variables can be assigned with different lag lengths as they enter the model (Pesaran,

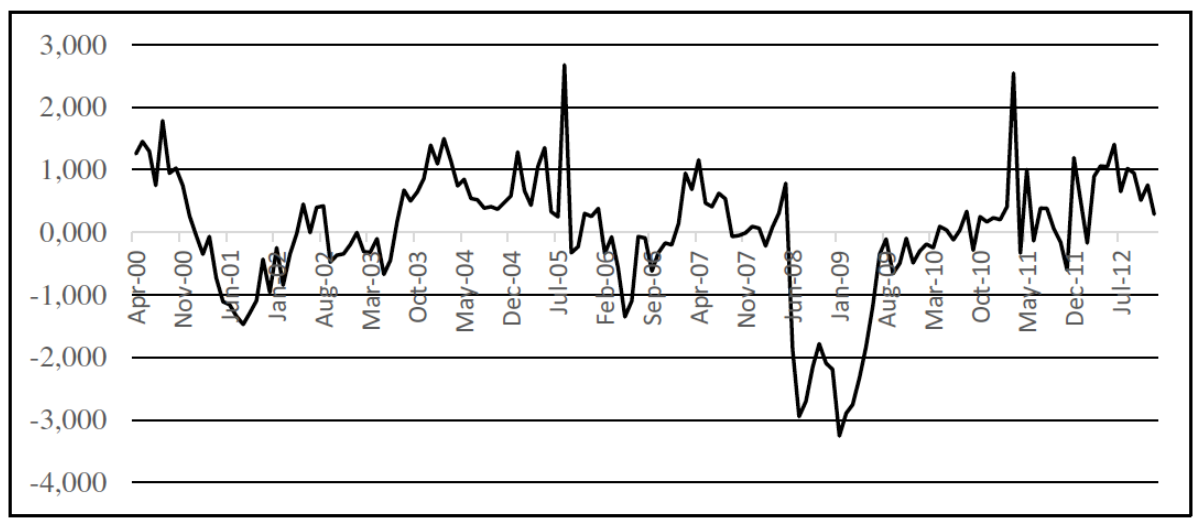

Figure 2: The movement of ISCI from 2000 to 2012. 
Table 7: Lags Selection by AIC and SC Criterion for ARDL Models

\begin{tabular}{|c|c|c|}
\hline Variables & AIC & SC \\
\hline \hline TURN, BLR, CPI, EER, IPI, M3 & 49.374 (lag 12) & 51.126 (lag 1) \\
\hline NIPO, BLR, CPI, EER, IPI, M3 & 33.312 (lag 12) & $34.542(\operatorname{lag} 1)$ \\
\hline RIPO, BLR, CPI, EER, IPI, M3 & $30.394(\operatorname{lag} 12)$ & $31.453(\operatorname{lag} 1)$ \\
\hline ADV, BKR, CPI, EER, IPI, M3 & $29.933(\operatorname{lag} 12)$ & $31.274(\operatorname{lag} 1)$ \\
\hline CSI, BLR,CPI, EER, IPI, M3 & $31.961(\operatorname{lag} 12)$ & $35.178(\operatorname{lag} 3)$ \\
\hline
\end{tabular}

Shin, \& Smith, 2001). Thus, the adoption of ARDL (p,q) models can be observed throughout this paper in testing different relationship hypotheses.

One of the initial steps to model ARDL $(p, q)$ is the maximum selection. Similar to VAR, the lag selection is determined by the suggestions from AIC and SC criterion. Nevertheless, as observed in previous analyses, SC proved to be consistent and provides the least lag for the model. Table 7 exhibits the sequence of variables modelled by VAR and the suggested lags by AIC and SC.

The four VAR models suggested a maximum of one lag by SC criterion. The following models are suggested with three lags by the $S C$ criterion; the TURN, BLR, CPI, EER, IPI, M3; the NIPO, BLR, CPI, EER, IPI, M3; RIPO, BLR, CPI, EER, IPI, M3 and the ADV, BLR, CPI, EER, IPI, and M3 model. While for the CSI, BLR, CPI, EER, IPI, M3 model. The main objective of testing the variables with $\operatorname{ARDL}(p, q)$ is essentially to obtain a cleaner measure of each proxy to represent investor sentiment, which results in an index that is free from the influence of macroeconomic fundamentals. The final ARDL $(p, q)$ models which are free from autocorrelation and heteroscedasticity problems are presented as follows:

$$
\begin{aligned}
& \Delta \text { TURN }_{\mathrm{t}}=9.445^{\star \star *}-0.117^{\star * *} \text { TURN }_{\mathrm{t}-1}-0.365^{* \star} \mathrm{BLR}_{\mathrm{t}-1}+ \\
& 2.69^{* *} \mathrm{EER}_{\mathrm{t}-1}+0.803^{* * *} \mathrm{M}_{\mathrm{t}-1}+\varepsilon \\
& R^{2}=0.089 ; D \cdot W=2.004 \\
& \Delta \mathrm{NIPO}_{\mathrm{t}}=-0.219^{* * *} \Delta \mathrm{NIPO}_{\mathrm{t}-1}-0.669^{* * *} \mathrm{NIPO}_{\mathrm{t}-1} \quad- \\
& 0.679^{* * *} \mathrm{BLR}_{\mathrm{t}-1}+0.128^{* * *} \mathrm{M} 3_{\mathrm{t}-1}+\varepsilon \\
& \mathrm{R}^{2}=0.464 ; \mathrm{D} \cdot \mathrm{W}=2.045 \\
& \Delta \mathrm{RIPO}_{\mathrm{t}}=-0.151^{*} \Delta \mathrm{RIPO}_{\mathrm{t}-1}+0.826^{* *} \Delta \mathrm{BLR}_{\mathrm{t}-1}- \\
& 0.194^{* * *} \mathrm{BLR}_{\mathrm{t}-1}+0.084^{* * *} \mathrm{EER}_{\mathrm{t}-1}+\varepsilon \\
& \mathrm{R}^{2}=0.526 ; \mathrm{D} . \mathrm{W}=2.013 \\
& \Delta \mathrm{ADV}_{\mathrm{t}}=14.244^{* *}-0.872^{\star * *} \mathrm{ADV}_{\mathrm{t}-1}+0.36^{* * *} \mathrm{BLR}_{\mathrm{t}-1}- \\
& 1.33^{* *} \mathrm{IPI}_{\mathrm{t}-1}+\varepsilon \\
& R^{2}=0.469 ; D \cdot W=2.04
\end{aligned}
$$

$\Delta \mathrm{CSI}_{\mathrm{t}}=-1.167-0.125^{* * *} \mathrm{CSI}_{\mathrm{t}-1}-0.048^{* *} \mathrm{BLR}_{\mathrm{t}-1}+$ $0.332^{\star *} \mathrm{EER}_{\mathrm{t}-1}+0.102^{* * *} \mathrm{M} 3_{\mathrm{t}-1}+\varepsilon$

$\mathrm{R}^{2}=0.01 ; \mathrm{D} \cdot \mathrm{W}=1.92$

From the finalised models, stock market turnover (TURN) is generally influenced by base lending rate (BLR), exchange rate (EER), and the circulation of broad money (M3). For instance, an increase in BLR will eventually have a negative impact on the stock market turnover. In contrast, the exchange rate and broad money circulation have positive impacts on the increase in stock market turnover. A change in the number of IPOs (NIPO) is also influenced by base lending rate (BLR) and circulation of broad money (M3). Similar with TURN, BLR has an inverse relationship whilst $\mathrm{M} 3$ has an adverse relationship with NIPO. Equation (14) shows the final RIPO model with the macroeconomic fundamentals where the change of BLR has an enormous impact on the change of IPO initial returns. Additionally, the exchange rate has minimal positive effect on the RIPO. A noteworthy relationship is the reverse result showed by the advance and decline stocks (ADV) with the macroeconomic fundamentals. Inconsistent with other proxies, ADV has a positive relationship with BLR and a significant inverse relationship with the industrial production index (IPI). Finally, consistent with TURN, the consumer sentiment index (CSI) seems to be affected by the movement of BLR, EER, and M3. Similar with TURN, NIPO, and RIPO, an increase in BLR significantly affects declining change in CSI. The final models are free from normality, serial correlation, and heteroscedasticity to meet the general assumptions of the ordinary least square method. The next step is to extract residuals of the models to construct a cleaner measure for the investor sentiment composite index which is discussed in the next section.

\section{Construction of Cleaner Measure for Investor Sentiment Composite Index $\left(\mathrm{ISCl}^{\mathrm{C}}\right)$ using Factor Analysis}

The residuals resulting from the regressions are extracted for further analyses which are considered as 
Table 8: Correlations between Current and One-Month Lag Proxies with FSI

\begin{tabular}{|c|c|c|c|c|c|c|c|c|c|c|}
\hline & $T U R N_{t}^{C}$ & $T U R N_{t-1}^{C}$ & $N I P O_{t}^{C}$ & $N I P O_{t-1}^{C}$ & $R I P O_{t}^{C}$ & $R I P O_{t-1}^{C}$ & $A D V_{t}^{C}$ & $A D V_{t-1}^{C}$ & $C S I_{t}^{C}$ & $C S I_{t-1}^{C}$ \\
\hline क्ष & $\begin{array}{c}0.153 \\
* *\end{array}$ & $\underset{* * *}{0.922}$ & $\underset{* *}{0.16}$ & -0.048 & $\begin{array}{c}0.26 \\
* * *\end{array}$ & $\begin{array}{c}0.136 \\
*\end{array}$ & $\underset{* * *}{0.293}$ & 0.067 & $\begin{array}{c}0.166 \\
* *\end{array}$ & $\begin{array}{c}0.921 \\
* * *\end{array}$ \\
\hline
\end{tabular}

Note:

i. ${ }^{* * *},{ }^{* *}$ and * denote $1 \%, 5 \%$ and $10 \%$, significant levels, respectively.

ii. Superscript $\mathrm{C}$ represents cleaner proxy net macroeconomic fundamentals.

cleaner proxies since they are free from the influence of macroeconomic fundamentals. The construction of a cleaner investor sentiment index follows the same procedures employed in constructing the ISCI with raw proxies earlier in this section. Each cleaner proxy incorporates a month lag and the current lag to construct the first stage index (FSI). Their correlations to the FSI are computed to determine the correct timing of each proxy that correlates to the cleaner index movement. From Table 8, each respective current proxy or one-month lag, whichever has a higher correlation with the first stage index, is then selected for construction of the cleaner investor sentiment composite index.

Observing from the significance of each cleaner proxy to the first stage index, the final selection of cleaner timing of proxies are $T U R N^{C}{ }_{t-1}, N_{I P O}{ }_{t}{ }_{t}, \operatorname{RIPO}^{C}$, $A D V^{C}{ }_{t}$ and $C S I_{t-1}^{C}$. Next, the proxies with respective timings are applied to the factor analysis with PCA extraction. Each of the index components has been standardised and coefficients are rescaled to a unit variance. There are two principal components that account for $67 \%$ of total cumulative variance in the cleaner proxies as exhibited in Table $\mathbf{9}$.

Table 9: Total Variance Explained by each Component

\begin{tabular}{|c|c|c|c|}
\hline \multicolumn{4}{|c|}{ Initial Eigenvalues } \\
\hline Component & Total & \% of Variance & Cumulative \% \\
\hline \hline 1 & 2.153 & 43.065 & 43.065 \\
\hline 2 & 1.198 & 23.953 & 67.018 \\
\hline
\end{tabular}

As suggested by Baker and Wurgler (2006, 2007, 2012), PC1 being the first principal components that account for the largest variation $\left(\sigma^{2}\right)$ of the underlying components is selected as the investor sentiment composite index. The factor loadings of PC1 and PC2 are exhibited in Table 10. Factor loading justifies the correlation of each cleaner proxy to each component whilst factor weights represents how much each proxy contributes to the constructed index. The factor weights are also used to calculate the factor scores for the construction of the investor sentiment composite index.
Table 10: Factor Loadings and Weights for PC1 and PC2

\begin{tabular}{|c|c|c|c|c|}
\hline \multirow{5}{*}{} & \multicolumn{5}{|c|}{ Frincipal Component } \\
\cline { 2 - 5 } & $\mathbf{1}$ & $\mathbf{2}$ & $\mathbf{1}$ & $\mathbf{2}$ \\
\hline \hline$T U R N_{t-1}^{C}$ & 0.957 & 0.135 & 0.44 & 0.05 \\
\hline$N I P O_{t}^{C}$ & -0.251 & 0.796 & -0.172 & 0.69 \\
\hline$R I P O_{t}^{C}$ & 0.297 & 0.704 & 0.092 & 0.575 \\
\hline$A D V_{t}^{C}$ & 0.399 & -0.191 & 0.200 & -0.188 \\
\hline$C S I_{t-1}^{C}$ & 0.963 & 0.113 & 0.445 & 0.031 \\
\hline $\begin{array}{l}\text { Note: } \\
\text { fundamentals. }\end{array}$ & & represents & cleaner proxy & net macroeconomic \\
\hline
\end{tabular}

Another interesting fact to address is the correlation between each proxy to the cleaner investor sentiment composite index illustrated by the second column of Table 10. Focusing on the first principal component (PC1), the one-month-lag CSI and TURN are highly correlated with PC1 respectively. For comparison purpose, the raw proxies' correlations with the cleaner investor sentiment composite index (ISCI) is exhibited in Table 8. Both cleaner measures of TURN and CSI maintain their timings of one-month lag to the index. CSI maintains the strongest correlation to the cleaner index, whilst TURN has a weaker net macroeconomic fundamental correlation. The finding suggests that CSI is the least macroeconomic fundamentally influenced proxy although it is compiled to measure the perception of consumers to the country's future economic condition. CSI may be a good representation of investor sentiment of the Malaysian stock market, however, the limitation is that CSI is available only on a quarterly basis. Additionally, major changes are observed in NIPO and RIPO where NIPO turns into an inverse relationship $(\rho=-0.251)$ in its correlation with the cleaner investor sentiment index.

Another interesting finding is the effect of a cleaner ADV measure in comparison to the raw proxy reported in the earlier section. As shown in Table 8, raw ADV correlates the least $(\rho=0.01)$ to the raw investor 


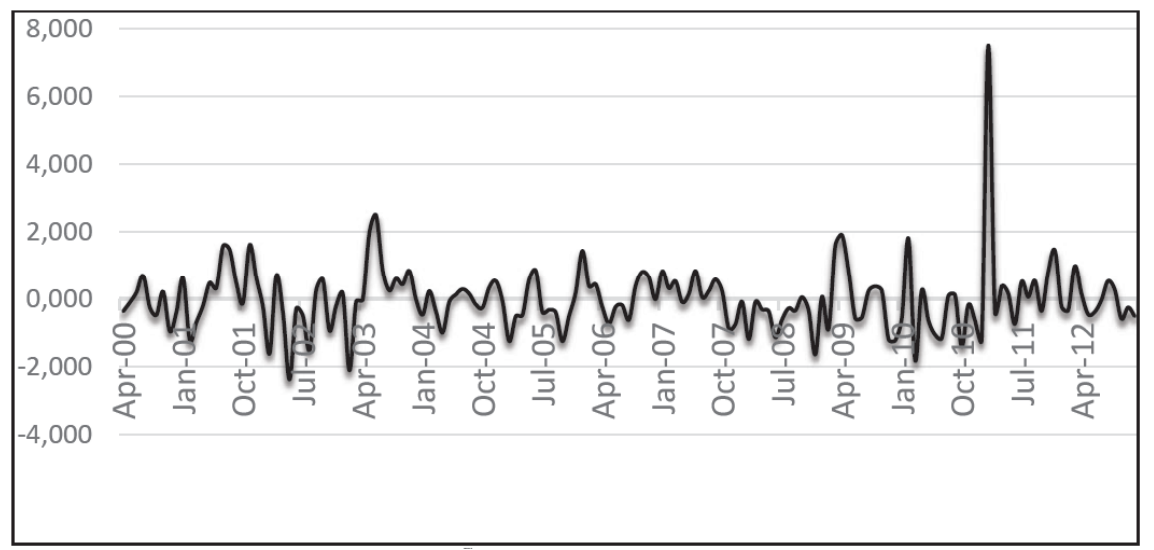

Figure 3: The $\mathrm{ISCl}^{\mathrm{C}}$ movement for the year 2000 to 2012.

sentiment composite index. However, it grows stronger after the effect of macroeconomic fundamentals are removed. These findings justify the proposition by Baker and Wurgler (2007) that proxies have to be individually regressed with the macroeconomic fundamentals, rather than the index as a whole. This is because each proxy may have a different and unique effect on the economy. Some proxies are strongly influenced by the economy whilst some proxies may be strongly influenced by non-fundamental factors. The $\mathrm{ISCl}^{\mathrm{C}}$ is computed as the weighted standardised cleaner proxies from Table 10 for 2000 to 2012. The parsimonious equation for cleaner sentiment index is therefore:

$$
\begin{aligned}
& I S C I_{t}^{C}=0.44 T U R N_{t-1}^{C}-0.172 N_{I P O}^{C}+0.092 R I P O_{t}^{C} \\
& +0.2 A D V_{t}^{C}+0.445 C S I_{t-1}^{C}
\end{aligned}
$$

The cleaner investor sentiment composite index $\left(\mathrm{ISCl}^{\mathrm{C}}\right)$ in monthly frequency is then plotted in a chart, as shown in Figure 3. From the chart it can be observed that throughout 2000 to 2012 , the $\mathrm{ISCl}^{\mathrm{C}}$ seems to be consistent except for a few episodes wherein the index remains in the negative territory for a number of months.

The next section investigates the relationship of the constructed $\mathrm{ISCl}$ and $\mathrm{ISCl}^{\mathrm{C}}$ to the leading stock market's barometer, the Kuala Lumpur Composite Index, its returns, and volatility.

\section{Investor Sentiment and the Stock Market Volatility during the 2008 Financial Crisis}

A co-integration test is not required to test the relationship for this section since all the three variables involved are stationary in nature. Hence, the VAR model is sufficient to model the relationship in subperiod analysis, particularly the 2008 global financial crisis. However, since the VAR model is atheoretical, the relationship between variables are better off examined by the Granger causality methodology. Table 11 exhibits the granger causal relationships between $I S C I, \quad I S C I^{C}$ and VKUALA LUMPUR COMPOSITE INDEX. The statistical hypothesis tested the following causal relationship.

H2: The investor sentiment composite index has no significant causal relationship with the volatility of Kuala Lumpur Composite Index during the period of the global financial crisis.

Table 11: Granger Causality between $\mathrm{ISCl} \mathrm{ISCl}^{\mathrm{C}}$ and Volatility of Kuala Lumpur Composite Index

\begin{tabular}{|c|c|c|c|}
\hline$Y_{t}$ & $X_{t-1}$ & $x^{2}$ & Lags \\
\hline \multirow[t]{18}{*}{ VKLCI } & $\mathrm{ISCl}$ & 0.615 & 1 \\
\hline & $\mathrm{ISCl}^{\mathrm{C}}$ & 0.11 & 1 \\
\hline & $\mathrm{ISCl}$ & 1.697 & 2 \\
\hline & $\mathrm{ISCl}^{\mathrm{C}}$ & 0.917 & 2 \\
\hline & $\mathrm{ISCl}$ & 4.541 & 3 \\
\hline & $\mathrm{ISCl}^{\mathrm{C}}$ & 2.051 & 3 \\
\hline & $\mathrm{ISCl}$ & 6.215 & 4 \\
\hline & $\mathrm{ISCl}^{\mathrm{C}}$ & 2.219 & 4 \\
\hline & $\mathrm{ISCl}$ & 7.989 & 5 \\
\hline & $\mathrm{ISCl}^{\mathrm{C}}$ & $10.599^{* \star *}$ & 5 \\
\hline & $\mathrm{ISCl}$ & 8.814 & 6 \\
\hline & $\mathrm{ISCl}^{\mathrm{C}}$ & $12.35^{\star \star \star}$ & 6 \\
\hline & $\mathrm{ISCl}$ & 10.2 & 7 \\
\hline & $\mathrm{ISCl}^{\mathrm{C}}$ & 9.359 & 7 \\
\hline & $\mathrm{ISCl}$ & $36.338^{* * *}$ & 8 \\
\hline & $\mathrm{ISCl}^{\mathrm{C}}$ & $21.616^{\star * *}$ & 8 \\
\hline & $\mathrm{ISCl}$ & $68.434^{* * *}$ & 9 \\
\hline & $\mathrm{ISCl}^{\mathrm{C}}$ & $49.313^{* * *}$ & 9 \\
\hline
\end{tabular}
(Vkuala Lumpur Composite Index)

Note:

i. *** denotes $1 \%$ significance level.

ii. Superscript $\mathrm{C}$ represents cleaner proxy net macroeconomic fundamentals. 
The existence of predictive power of both Investor Sentiment Composite Index and the Cleaner Investor Sentiment Composite Index to the volatility of Kuala Lumpur Composite Index is shown by its apparent manifestation during a longer horizon. The result is consistent with previous findings for 2000 to 2012 . Table 11 shows that at lag five, $\mathrm{ISCl}^{\mathrm{C}}$ significantly granger caused the volatility of KUALA LUMPUR COMPOSITE INDEX. The causal relationship continues at lag six, disappeared at lag seven, and resumed from lag eight to lag nine. In conclusion, during the 2008 global financial crisis, the effect of investor sentiment still exists although the effect is not. This finding can be explained by the limited number of samples in this study. These findings, one way or another have contributed to the existence of investor sentiment in predicting stock market volatility. This relationship is evident in the studies of European and the Unites States' stock markets behaviour by Zouaoui, Nouyrigat, and Beer (2011) where the study found that the investor sentiment was more noticeable in countries that are culturally practised herd-like behaviour, over-reaction with inefficient financial markets.

\section{CONCLUSION}

The study focuses on the behaviour of stock market volatility during the 2008 global crisis. It was a period of crisis in which higher volatility and uncertainty of the stock market was observed in Malaysian stock market. Although economic data in Malaysia did not show any alarming figures during that period, investors displayed reactions that were reflected by the behaviour of United States' stock market almost instantaneously. The movement of all major stock market indices was unstable for a long period during the crises. Thus, the contagion effect on the volatility of the Malaysian stock market was inevitable. The volatility reached the highest in 2008 due to the effect of global financial crisis.

Consistent with the notion that excess volatility may be initiated by the irrational behaviour of investors, this study observed no significant association between macroeconomic fundamentals to the stock market volatility during these periods. The findings of this study have examined with the suggestions made by previous studies (Shiller, 1981; Zakaria \& Shamsuddin, 2012) that the excessive volatility of the stock market may be explained by the irrational behaviour of investors'. These findings may assist practitioners and policymakers in formulating strategies and policies in critical situation to avoid crises. Stock market regulators may apply effective approaches to eradicate irrational reactions from stock market sentiments. Additionally, in expectation of the irrational movement of the stock prices, an early intervention from policymakers can be carried out. With enlightenment from the findings of this study, investors may equip themselves with strategies prior to available announcement hence, able to carry out prudent measures, either to avoid entering the stock market during high volatility, or to take advantage of fluctuations in price and gain abnormal returns resulting from price spreads in short term trading.

\section{REFERENCES}

Aggarwal, R., Leal, R., \& Hernandez, L. (1993). The Aftermarket Performance of Initial Public Offerings in Latin America. The Journal of the Financial Management Association, 22(1), 4253. https://doi.org/10.2307/3665964

Angabini, A., \& Wasiuzzaman, S. (2010). Impact of the global financial crisis on the volatility of the Malaysian stock market. In International Conference on E-Business, Management and Economics. (pp. 1-26). https://doi.org/10.2139/ssrn.1659548

Angabini, A., \& Wasiuzzaman, S. (2011). GARCH models and financial crisis a study of the malaysian stock market. The International Journal of Applied Economics and Finance, 5(3), 226-236. https://doi.org/10.3923/ijaef.2011.226.236

Bai, J., \& Perron, P. (1998). Estimating and testing linear models with multiple structural changes. Econometrica, 66(1), 47-78. https://doi.org/10.2307/2998540

Bai, J., \& Perron, P. (2003a). Computation and analysis of multiple structural change models. Journal of Applied Econometrics, 18(1), 1-22. https://doi.org/10.1002/jae.659

Bai, J., \& Perron, P. (2003b). Critical values for multiple structural change tests. Econometrics Journal, 6, 72-78. https://doi.org/10.1111/1368-423X.00102

Baker, M. P., \& Stein, J. (2004). Market liquidity as a sentiment indicator. Journal of Financial Markets, 7(3), 271-299. https://doi.org/10.1016/j.finmar.2003.11.005

Baker, M. P., \& Wurgler, J. (2006). Investor Sentiment and the Cross-Section of Stock Returns. The Journal of Finance, 61(4), 1645-1680. https://doi.org/10.1111/j.1540-6261.2006.00885.x

Baker, M. P., Wurgler, J., \& Yuan, Y. (2012). Global, Local, and Contagious Investor Sentiment. Journal of Financial Economics, 104(2), 272-287. https://doi.org/10.1016/j.jfineco.2011.11.002

Baker, M., \& Wurgler, J. (2007). Investor Sentiment in the Stock Market. Journal of Economic Perspectives, 21(2), 129-151. https://doi.org/10.1257/jep.21.2.129

Bandopadhyaya, A., \& Jones, A. L. (2006). Measuring investor sentiment in Equity Markets. Journal of Asse, 7(3/4), 208215. https://doi.org/10.1057/palgrave.jam.2240214

Beltratti, A., \& Morana, C. (2002). Breaks and Persistency : Macroeconomic Causes of Stock Market Volatility. Journal of Econometrics, 131(1-2), 1-66. https://doi.org/10.1016/i.jeconom.2005.01.007 
Brown, G. W., \& Cliff, M. T. (2005). Investor Sentiment and Asset Valuation. Journal of Business, 78(2), 405-440. https://doi.org/10.1086/427633

Chan, W., Frankel, R., \& Kothari, S. (2004). Testing behavioral finance theories using trends and consistency in financial performance. Journal of Accounting and Economics, 38, 350.

https://doi.org/10.1016/j.jacceco.2004.07.003

Davis, N., \& Kutan, A. M. (2003). Inflation and output as predictors of stock returns and volatility: international evidence. Applied Financial Economics, 13(9), 693-700. https://doi.org/10.1080/09603100210139429

Derrien, F. (2005). IPO Pricing in " Hot" Market Conditions: Who Leaves Money on the Table? The Journal of Finance, 60(1), 487-521. https://doi.org/10.1111/j.1540-6261.2005.00736.x

Diebold, F. X., \& Yilmaz, K. (2010). Macroeconomic Volatility and Stock Market Volatility, Worldwide. In T. Bollerslev, J. Russel, \& M. Watson (Eds.), Volatility and Time Series Econometrics:Essays in Honor of Robert F. Engle (pp. 97116). Oxford University Press.

https://doi.org/10.1093/acprof:oso/9780199549498.003.0006

Dorn, D. (2009). Does Sentiment Drive the Retail Demand for IPOs? Journal of Financial and Quantitative Analysis, 44(1), 85. https://doi.org/10.1017/S0022109009090024

Engle, R. F., Ghysels, E., \& Sohn, B. (2013). Stock Market Volatility and Macroeconomic Fundamentals. Review of Economics and Statistics, 95(3), 776-797. https://doi.org/10.1162/REST_a_00300

Fisher, K. L., \& Statman, M. (2003). Consumer confidence and stock returns. Journal of Portfolio Management, 30(1), 115. https://doi.org/10.3905/jpm.2003.319925

French, K. R., Schwert, G. W., \& Stambaugh, R. F. (1987). Expected stock returns and volatility. Journal of Financial Economics, 19, 3-29. https://doi.org/10.1016/0304-405X(87)90026-2

Hog, R. V., \& Tanis, E. A. (2005). Probability and Statistical Inference (7th ed.). Prentice - Hall Inc.

Kim, K., \& Nofsinger, J. (2008). Behavioral finance in Asia. PacificBasin Finance Journal, 16(1-2), 1-7. https://doi.org/10.1016/j.pacfin.2007.04.001

Law, S. H. (2006). Has Stock Market Volatility in the Kuala Lumpur Stock Exchange Returned to Pre-Asian Financial Crisis Levels ? ASEAN Economic Bulletin, 23(2), 212-229. https://doi.org/10.1355/AE23-2E

Lemmon, M., \& Portniaguina, E. (2006). Consumer Confidence and Asset Prices: Some Empirical Evidence. The Review of Financial Studies, 19(4), 1499-1529. https://doi.org/10.1093/rfs/hhj038
Lowry, M. (2003). Why does IPO volume fluctuate so much? Journal of Financial Economics, 67, 3-40. https://doi.org/10.1016/S0304-405X(02)00230-1

Neal, R., \& Wheatley, S. M. (1998). Do measures of investor sentiment redict returns. Journal of Financial and Quantitative Analysis, 33(4). https://doi.org/10.2307/2331130

Officer, R. R. (1973). The Variability of the Market Factor of the New York Stock Exchange. Journal of Business, 46. https://doi.org/10.1086/295551

Pesaran, H., Shin, Y., \& Smith, R. (2001). Bounds testing approaches to the analysis of level relationships. Journal of Applied Econometrics, 16(3), 289-326. https://doi.org/10.1002/jae.616

Rahman, A. A., Sidek, N. Z. M., \& Tafri, F. H. (2009). Macroeconomic determinants of Malaysian stock market. African Journal of Business Management, 3(3), 95-106.

Ritter, jay R., \& Welch, I. (2002). A Review of IPO Activity, Pricing and Allocations. The Journal of Finance, 57(4), 1795-1828. https://doi.org/10.1111/1540-6261.00478

Schmeling, M. (2009). Investor sentiment and stock returns: Some international evidence. Journal of Empirical Finance, 16(3), 394-408. https://doi.org/10.1016/j.jempfin.2009.01.002

Schwert, G. W. (1989). Why Does Stock Market Volatility Change Over Time? The Journal of Finance, 44(5), 1115-1153. https://doi.org/10.1111/j.1540-6261.1989.tb02647.x

Shiller, R. J. (1981). Do Stock Prices Move Too Much to be Justified by Subsequent Changes in Dividends? The American Economic Review, 71(3), 421-436. https://doi.org/10.3386/w0456

Shiller, R. J. (1987). The Volatility of Stock Market Prices. Science, New Series, 235(4784), 33-37. https://doi.org/10.1126/science.235.4784.33

Yung, C., Colak, G., \& Wang, W. (2008). Cycles in the IPO market. Journal of Financial Economics, 89(1), 192-208. https://doi.org/10.1016/j.jfineco.2007.06.007

Zakaria, Z., \& Shamsuddin, S. (2012). Empirical Evidence on the Relationship between Stock Market Volatility and Macroeconomics Volatility in. Journal of Business Studies Quarterly, 4(2), 61-71.

Zouaoui, M., Nouyrigat, G., \& Beer, F. (2011). How Does Investor Sentiment Affect Stock Market Crises? Evidence from Panel Data. Financial Review, 46(4), 723-747. https://doi.org/10.1111/j.1540-6288.2011.00318.x

DOI: https://doi.org/10.6000/1929-7092.2019.08.65

(C) 2019 Nathrah Yacob; Licensee Lifescience Global.

This is an open access article licensed under the terms of the Creative Commons Attribution Non-Commercial License (http://creativecommons.org/licenses/by-nc/3.0/) which permits unrestricted, non-commercial use, distribution and reproduction in any medium, provided the work is properly cited. 